\title{
Plasma Cell Dyscrasia in 105 Japanese Patients with Systemic Amyloidosis
}

\author{
Takashi Isobe, MD, Mokoto Tomita, MD, Junji Matsumoto, MD \\ and Takuo Fujita, MD
}

\begin{abstract}
Total 105 Japanese cases of systemic amyloidosis were analysed in terms of Congo red staining with potassium permanganate, anti-amyloid serum staining by immunoperoxidase and the occurrence of monoclonal proteins (ie. plasma cell dyscrasia, PCD). Thirty three cases of primary type amyloidosis and 22 cases of myeloma-associated amyloidosis were mostly associated with PCD, with 3 exceptional cases without PCD. In contrast, 45 cases of secondary type amyloidosis were demonstrated as AA type, with no association of PCD. Predominance of lambda light chain in amyloidosis was contrasted to kappa chain predominance among the non-amyloidotic myeloma cases.
\end{abstract}

Key Words: Amyloid fibril proteins, Monoclonal protein, PCD, Congo red staining, Potassium permanganate, AA, AL, Lambda chain, Kappa chain

\section{INTRODUCTION}

The nature of amyloidosis has been extensively explored over the last 2 decades. The dissolution of the anyloid materials with denaturing solvents opened up a new field of investigation by a wide variety of chemical and physical techniques in laboratories ${ }^{1,2)}$. Though the unifying definition of anyloid utilizes the $\beta$-pleated sheet structure, a clinical approach to this disease is still hampered by the variety of amyloid fibril proteins and their insolubility. In the present paper, cases of systemic amyloidosis among Japanese were compared to previously published series of amyloidosis in $\mathrm{USA}^{3)}$, in terms of frequency of monoclonal immunoglobulin, incidence of positive staining for anti AA and other histochemical stainings ${ }^{2)}$.

\section{MATERIALS AND METHODS}

One hundred five cases of systemic amyloidosis, excluding localized single organ amyloid, experienced during the past 7 years, were studied. Some of these patients were hospitalized in the Kobe University Hospital, and clinical materials such as serum, urine and tissue of other patients were brought to our laboratory. Amyloidosis was documented in all cases by tissue biopsies and/or autopsied tissue sections with Congo red and other specific staining methods, polarization microscopy and, in some cases, electron microscopy. Multiple serum samples and urine collections were stored frozen at $-20^{\circ} \mathrm{C}$, thus permitting repeated analyses of specimens. All serum and urine samples were studied by electrophoresis (cellulose acetate, barbital buffer, $\mathrm{pH}$ 8.6) and by immunoelectrophoretic analyses ${ }^{3)}$. Urine samples were initially screened for protein by 20 percent sulfosalicylic acid. Albustix, which were commonly used for urine protein screening, are grossly unreliable for the detection of BJ protein and should not be relied on for routine testing. All samples showing a positive reaction with 20 percent sulfosalicylic acid, even a faint trace, were concentrated 30 times by osmodialysis against polyethylene glycol 6,000 before anlyses. The characteristic electrophoretic finding of a narrow peak in the $\alpha_{2}-\gamma$ mobility range generally represented the first evidence of BJP. In 15 patients in the present series, however, the $\mathrm{BJP}$ was associated with and electrophoretically masked by nonspecific protein-

From The Third Division, Department of Medicine, Kobe University School of Medicine, Kobe, Japan.

Received for publication December 27, 1982.

Reprint request to: Takashi Isobe, MD, The Third Department of Internal Medicine,

Kobe University Hospital, 12, 7-chome Kusunokicho, Chuo-ku, Kobe, 650, Japan. 
uria, and in these cases BJP could only be demonstrated by immunoelectrophoresis. The classic heat-precipitation method were therefore not invariably employed in this study.

The criterion for BJP-containing urine was the demonstration of an excess quantity of one type of light chain $(\kappa$ or $\lambda)$ without any reaction with heavy chains $(\gamma, \alpha, \mu, \delta, \epsilon)$. Because of the heterogeneity of light chains related to primary structural differences in the variable and constant regions, several antisera prepared against different BJP $K$ 's and BJP $\lambda$ 's mainly raised in our laboratory were used. Since all these antisera contained antibodies to both V-and C-regions, it is possible that some incomplete BJP's lacking part of the Cregion may be detectable by antibodies to $\mathrm{V}$ region antigenic determinants in these antisera.

Amyloid laden tissues were formalin-fixed, paraffin-embedded, cut at $6 \mu \mathrm{m}$, deparaffinized in xylol to absolute alcohol, rinsed in running tap water and allowed to dry in the air. Two duplicate sections were used. One slide was directly stained with alkaline Congo red and the other was incubated with potassium permanganate solution for 2 minutes prior to being stained with Congo red. The potassium permanganate was made with equal volumes of 0.3 percent $\mathrm{H}_{2} \mathrm{SO}_{4}$ and 5 percent $\mathrm{MKnO}_{4}{ }^{4)}$. All Congo red-stained sections were examined using polarization as well as conventional microscopy. When Congo red staining was decreased or disappeared on amyloid deposits after $\mathrm{KMnO}_{4}$ treatment, it was designated as sensitive (to $\mathrm{MKnO}_{4}$ ), whereas no change was observed in staining in case of resistant.

Antiserum to amyloid was raised by repeated immunizations in the rabbits in our laboratories. Amyloid fibril proteins of A type were extracted and purified as described previously from the patient with systemic amyloidosis ${ }^{5)}$. Both $\operatorname{AL}(\kappa)$ and $\operatorname{AL}(\lambda)$ were extracted from the liver tissues of amyloid patients with $\mathrm{BJP} K$ and $\mathrm{BJP} \lambda$, respectively. Immunizations of amyloid protein were done subcutaneously into rabbits with emulsified solution of equal volume of $1 \mathrm{mg} / \mathrm{ml}$ amyloid protein in phosphate buffered saline and complete Freund adjuvants.

Immunoperoxidase staining was performed by peroxidase-conjugated antibody using indirect methods ${ }^{6)}$. The primary rabbit antiserum for amyloid protein is applied initially, followed by a peroxidase-antibody conjugate from the goat, directed against the rabbit immunoglobulin.

\section{RESULTS}

Systemic amyloidosis was diagnosed on the basis of clinical manifestations characteristic to amyloidosis such as macroglossia, cardiac amyloid with ECG abnormalities, thyroid enlargement, splenomegaly, or cutaneous amyloid deposits, in combination with biopsied and/or autopsied findings. Total 105 cases of systemic amyloidosis were then subdivided into 4 groups. Primary type without any significant antecedent disorders was found in 33 cases, amyloidosis associated with definite myeloma in 22 cases, amyloidosis secondary to other disorders in 45 cases and familial amyloid polyneuropathy of Japanese type in 5 cases. As to clinical background in 45 cases of socalled secondary amyloidosis, there were 27 cases $(60.0 \%)$ of connective tissue diseases, 11 cases $(24.5 \%)$ of infectious disorders, 3 cases $(6.6 \%)$ of nephrotic syndrome, one case $(2.2 \%)$ of Hodgkin's disease and 3 cases $(6.6 \%)$ of undefined antecedent disorders. The connective tissue and autoimmune diseases in these 27 cases included rheumatoid arthritis in 18 cases, juvenile rheumatoid arthritis in 2, Sjögren syndrome in 3, chronic thyroiditis in 2 and Bechet's disease and SLE in 1 case each. Infectious diseases in these 11 cases consisted of 6 cases of pulmonary infectious including bronchiectasia, 2 cases of cholecystitis, one case of pulmonary tuberculosis, pyelonephritis and hepatitis respectively.

It is quite difficult in some amyloid cases to differentiate primary amyloidosis from secondary

Table 1. The frequency of sensitive potassium permanganate reaction, positive $\mathrm{AA}$ by immunoperoxidase and frequency of the monoclonal proteins in the serum and/or in the urine among 105 cases with systemic amyloidosis.

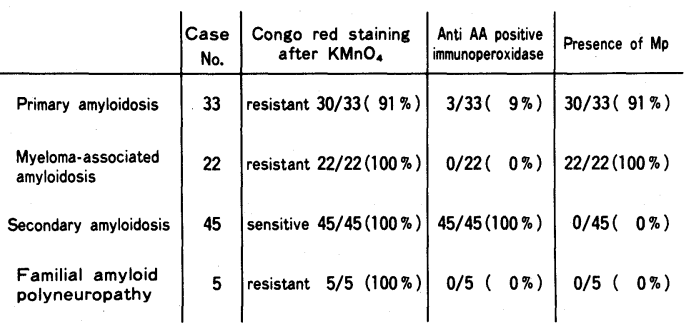

Jap J Med Vol 22, No 2 (April 1983) 
type from the clinical and immunochemical points of view. Table 1 summarized the frequency of sensitive potassium permanganate reaction i.e. disappearance of Congo red staining, positive reaction with anti AA by immunoperoxidase and frequency of the presence of monoclonal proteins in the serum and/or in the urine. There is a similarity between primary amyloidosis and myelomaassociated amyloidosis with respect to highly resistant reaction to $\mathrm{KMnO}_{4}$, negative staining to anti AA and strong association of M-protein. This similarity between two groups may well be based on the same nature of amyloid protein (immunoglobulin origin). The result of these 2 groups in Table 1 is clearly contrasted to the data in patients with secondary amyloidosis. This indicates the differences of amyloidosis groups as to amyloid fibril proteins, with different histochemical and immunochemical properties. In these circumstances, it is very interesting that there were 3 exceptional cases of AA type without monoclonal proteins. These 3 cases are therefore classified into AA type in addition to 45 cases of secondary amyloidosis. On the other hand, all of the 22 cases of meylomaassociated amyloidosis and 30 cases of primary amyloidosis excluding 3 cases of AA type are classified into amyloidosis with plasma cell dyscrasia (PCD) and probably AL type (amyloid of immunoglobulin light chain origin). The immunoperoxidase study with a single antiserum for $\mathrm{AL}$ $(\kappa)$ and a single other for AL $(\lambda)$ are performed in all cases. However, the positive results were very rarely found among 52 cases. Only 3 cases were positive for anti $\operatorname{AL}(\kappa)$, whereas only 5 cases were positive for anti AL $(\lambda)$. This may be explained partially by the deficiency of sufficient antigenic determinants of different light chain subgroups, since 3 subgroups in kappa chains and 6 subgroups in lambda chains have been clarified so far in the literature, respectively.

As to cases of familial amyloid polyneuropathy, all 5 cases showed negative and no evidence of Mproteins resembling secondary amyloidosis, from which all 5 cases were different regarding Congo red staining after potassium permanganate. This again may indicate the differences of amyloid fibril proteins between secondary-AA type amyloidosis and familial amyloid polyneuropathy.

Table 2 shows the frequency of specific M-
Table 2. The frequency of specific M-proteins in the 52 cases of systemic amyloidosis with plasma cell dyscrasia (monoclonal gammopathy).

\begin{tabular}{l|c|c|c} 
& $\begin{array}{c}\text { Amyloidosis } \\
\text { with PCD } \\
1982\end{array}$ & $\begin{array}{c}\text { Amyloidosis } \\
\text { with PCD } \\
1974\end{array}$ & $\begin{array}{c}\text { Myeloma } \\
1971\end{array}$ \\
\hline Case No. & 52 & 88 & 351 \\
\hline BJ $x$ only & $7(13.5 \%)$ & $21(23.9 \%)$ & $(13.1 \%)$ \\
BJ $\lambda$ only & $9(17.3)$ & $25(28.4)$ & $(12.0)$ \\
IgG only & $7(13.5)$ & $10(11.4)$ & $(31.9)$ \\
IgG+B $x$ & $3(5.8)$ & $3(3.4)$ & $(9.1)$ \\
IgG+BJ $\lambda$ & $8(15.4)$ & $9(10.2)$ & $(11.1)$ \\
IgA only & $5(9.6)$ & $7(8.0)$ & $(13.7)$ \\
IgA+B $x$ & $2(3.8)$ & $1(1.1)$ & $(3.4)$ \\
IgA+B $\lambda$ & $6(11.5)$ & $1(1.1)$ & $(4.8)$ \\
IgD only & $1(1.9)$ & $1(1.1)$ & $(0)$ \\
IgD+BJ $x$ & $0(0)$ & $0(0)$ & $(0)$ \\
IgD+BJ $\lambda$ & $0(0)$ & $1(1.1)$ & $(0.9)$ \\
IgM only & $1(1.9)$ & $7(8.0)$ & $(0)$ \\
IgM+B $x$ & $1(1.9)$ & $2(2.3)$ & $(0)$ \\
IgM+B $\lambda$ & $2(3.8)$ & $0(0)$ & $(0)$ \\
\hline B $J x$ & $13 / 52(25.0 \%)$ & $27 / 88(30.7 \%)$ & $(25.0 \%)$ \\
BJ $\lambda$ & $25 / 52(48.1 \%)$ & $36 / 88(40.9 \%)$ & $(28.8 \%)$ \\
& & &
\end{tabular}

Table 3. Comparison of the ratio of kappa to lambda chain, among amyloidosis and myeloma patients.

\begin{tabular}{c||c|c||c|c|c||} 
& Amyloid & Amyloid & Myeloma & Myeloma & Myeloma \\
\hline & $\begin{array}{c}\text { Isobe } \\
\text { Osserman } \\
1974\end{array}$ & $\begin{array}{c}\text { Isobe } \\
1982\end{array}$ & $\begin{array}{c}\text { Japan } \\
\text { oncology } \\
\text { series } \\
1980\end{array}$ & $\begin{array}{c}\text { Pruzanski } \\
1976\end{array}$ & $\begin{array}{c}\text { Outeirino } \\
1976\end{array}$ \\
\hline Country & USA & Japan & Japan & Canada & Spain \\
\hline Case No. & 88 & 52 & 623 & 632 & 100 \\
\hline$x: \lambda$ & $0.75: 1$ & $0.52: 1$ & $1.5: 1$ & $1.3: 1$ & $1.3: 1$ \\
\hline
\end{tabular}

proteins in the 52 cases of amyloidosis with PCD out of 105 cases in the present study. Comparison is also made in Table 2 among 52 cases and two other studies, comprising of 88 cases of amyloidosis associated with PCD in 1974 series in New York by us ${ }^{3}$ and 351 cases of myeloma cases without amyloid in 1971 series in New York by us $^{7)}$. Although some differences between 2 amyloid series in Japan and in New York are found, particulary noteworthy is the relatively higher proportion of cases with BJP $\lambda(25.0$ percent, as compared with 48.1 percent in Japanese series. 30.7 percent, as compared with 40.9 percent in New York series). In this regard, the myeloma series represent almost equal frequency of BJP $\kappa$ versus BJP $\lambda$ (25.0 percent, as compared with 
28.8 percent). The higher frequency of BJP $\lambda$ in both amyloidosis series than in myeloma series is statistically significant $(\mathrm{P}<0.005)$.

Table 3 compares the ratio of kappa to lambda, among 2 amyloidosis study series and 3 myeloma study series in different countries ${ }^{8-10}$ ). Relatively higher predominances of lambda type in amyloidosis series are again contrasted to the myeloma series.

\section{DISCUSSION}

The diversity of the major protein component of amyloid fibrils has been clarified in the past 2 decades $^{1,2)}$. Meanwhile, the description of old classification for amyloidosis, such as primary, secondary, myeloma-associated, localized and familial has been preferably used by many investigators in the past. Once the nature of the amyloid fibril protein is known, a simplified schema was recommended for the preliminary classification of amyloidosis to describe the disease by the protein term. The development of peroxidaseenzyme antibody method (immunoperoxidase method) could permit one way to make a new classification of systemic amyloidosis ${ }^{2,6)}$ since cases of so-called acquired or secondary systemic amyloidosis requirely encounter no clear relationship of the amyloidosis to the concomitant disease of rarely no underlying disease detected at all ${ }^{1,3)}$. In addition, Congo red staining after potassium permanganate has been accepted to many investigators as a simple and reproducible histochemical method, based on the affinity for Congo red dye after exposure to potassium permanganate to amyloid samples in different preservatives, distinguishing amyloid protein AA from other chemical types ${ }^{4)}$.

Table 1 in the present study showed the result of both histochemical and immunochemical methods on 105 cases of systemic amyloidosis in Japan. As a result, anti AA proved to be extremely specific for the relevant type of amyloid in all specimens from all patients with secondary amyloidosis. On the contrary, two anti AL antisera for both kappa type and lambda type gave low positive reactions for the relevant type of amyloid from patients with plasma cell dyscrasias. This discrepancy between low positive reactions with anti $\mathrm{AL}$ and positive M-proteins may be attributed to the deficient antigenic determinants of different subgroups of light chains of immunoglobulins or to the different conformational structures between intact BJP (L-chain) an amyloid light chain fragments.

Therefore, there is so far no definite method to specify the chemical nature of amyloid. In this regard, different antisera for different light chain subgroups are expected to determine subgroups of light chains immunochemically and immunohistochemically.

As to the frequency of specific M-proteins in the 105 cases of systemic amyloidosis, there was no single case with M-protein among secondary amyloidosis and familial amyloid polyneuropathy. The data are relevant to amyloid protein different from protein $\mathrm{AL}$. Table 2 compares the frequency of specific M-proteins in $\mathbf{5 5}$ cases of amyloidosis to another amyloidosis series and myeloma (nonamyloid) series. Particularly noteworthy in these amyloidosis group is the relatively higher proportion of cases with BJP lambda type. Similar result was also obtained by Kyle and Bayrd ${ }^{11)}$, who reviewed a large series of 236 cases with amyloidosis. They summarized serum M-proteins in amyloidosis with a ratio of one kappa to 1.70 lambda (ie, $\kappa: \lambda=0.59: 1$ ). They also summarized urinary M-proteins in amyloidosis with a ratio of one kappa to 1.42 lambda (ie, $\kappa: \lambda=0.71: 1$ ). Predominance of lambda chain was also demonstrated as seen in other studies ${ }^{12-14)}$. This observation is also consistent with the report by Glenner et $\mathrm{al}^{1)}$ that a relatively high proportion of the proteins isolated from amyloids had blocked $\mathrm{N}$ termini. This feature is characteristic of $\lambda$ light chain. Although unusual amino acid sequences, substitutions and deletions have been noted in several amyloid-fibril proteins of the immunoglobulin type, no uniform peculiarity that could be used to identify light chains with any amyloidogenic proclivity has been found. Biochemical studies on amyloid deposits revealed that the amyloid fibril proteins are fragments most likely derived not from an intact immunoglobulin protein or a light-chain fragment, but from an intact homogeneous circulating light chain (ie. a serum $\mathrm{BJP})^{1)}$.

Although the factors responsible for initiating and perpetuating the process of progressive protein 
deposition remain to be elucidated, amyloidrelated BJ proteins might be represent fragments of autoantibodies and therefore the initial binding to specific tissues could be an immunologic interaction. The subsequent progressive accumulation of the polymers is more probably due to the intrinsic polymerization tendencies of certain light chains by non-covalent bonding ${ }^{3)}$. Through enzymatic breakdown, polymers are formed that are insoluble under physiologic conditions, which in fact are resistant to therapeutic approaches among patients. Further biochemical and physical elucidation of amyloidogenic proteins and amyloidogenesis may clarify the mechanism of amyloidosis and open up a more effective way to treat amyloidosis.

\section{REFERENCES}

1) Glenner GG: Amyloid deposits and amyloidosis. The $\beta$-fibrilloses. N Engl J Med 302: 1283, 1333, 1980.

2) Glenner GG, Costa PP, Freitas AF: Amyloid and amyloidosis. Proceedings of the Third International Symposium on Amyloidosis. Excerpta Medica, Amsterdam 1980.

3) Isobe T, Osserman EF: Patterns of amyloidosis and their association with plasma-cell dyscrasia, monoclonal immunoglobulins and Bence Jones proteins, N Engl J Med 290: 473, 1974.
4) Wright JR, Calkins E, Humpherey RL: Potassium permanganate reaction in amyloidosis. Histologic method to assist in differentiating forms of this disease. Laboratory Invest 36: 274, 1977.

5) Isobe $T$, Imura $H$, Kyogoku $M$ : Amyloid fibril protein of AA type from the thyroid in a 16-yearold patient with systemic amyloidosis. Acta Haematol Jap, 40: 550, 1977.

6) Taylor GR: Immunoperoxidase Techniques. Arch Pathol Lab Med 102: 113, 1978.

7) Osserman EF: Multiple myeloma and related plasma cell dyscrasias in Immunological Disease. ed by Samter M. pp. 499-529, 1978, Little Brown and Co.

8) Pruzanski W: Clinical manifestations of multiple myeloma: relation to class and type $\mathrm{M}$ component. Can Med Assoc J 140: 896, 1976.

9) Quteirino J, Sanchez FJ, Ortiz MF et al: Non-macroglobulinaemic plasma cell dyscrasias in haematological analysis in 100 cases. Sanger 21: 296, 1976.

10) Japan hematological oncology group committee: 1972-1977. Jap J Clin hematology, 1981.

11) Kyle RA, Bayrd ED: Amyloidosis: Review of 236 cases. Medicine 54: 271, 1975.

12) Stone MJ, Frenkel EP: The clinical spectrum of light chain myeloma. A study of 35 patients with special reference to the occurrence of amyloidosis. Am J Med 58: 601, 1975.

13) Pick AL, Fröhlichmann, Lavie G, Duczyminer M, Skvarie F: Clinical and Immunochemical studies of 20 patients with amyloidosis and plasma cell dyscrasia. Acta haemat. 66: 154, 1981.

14) Tosato G, Fagiolo E: Bone marrow amyloid in patients with M-components. Tumori 63: 69, 1977. 